\title{
The Effectiveness Analysis of Loxon Body Mask on Hepatocellular Carcinoma Cases Using a Rapid ARC Technique against the X, Y, and $\mathrm{Z}$ Coordinate On Board Imager in Radiation Therapy
}

\author{
Samsun $^{1}$, Nursama Heru Apriantoro ${ }^{1}$, Sriyatun ${ }^{1}$, Wahyu Hidayat ${ }^{1}$, Rudi Kurniawan ${ }^{2} \&$ Singgang Pangestu $^{1}$ \\ ${ }^{1}$ Department of Radiodiagnostic and Radiotherapy, Politeknik Kesehatan Kemenkes Jakarta II, Jakarta, \\ Indonesia \\ ${ }^{2}$ Radiology Unit, MRCCC Hospital of Semanggi, Jakarta, Indonesia \\ Correspondence: Samsun, Department of Radiodiagnostic, Politeknik Kesehatan Kemenkes Jakarta II, Hang \\ Jebat III/F-3, Jakarta 12120, Indonesia. E-mail: aiman_052005@yahoo.com
}

Received: August 23, 2019

doi:10.5539/mas.v13n10p122
Accepted: September 23, 2019

Online Published: September 24, 2019

\begin{abstract}
Immobilization tools are used to reduce the movement during irradiation; one of the immobilization tools is Loxon Body Mask applied on the abdominal and pelvic regions. This study aimed to analyze the effectiveness of Loxon Body Mask against changes in X, Y and Z coordinates. The study took place in the Radiotherapy Installation of MRCCC Siloam Hospital Semanggi. Data were obtained from 10 secondary data samples of HCC patients with 20 times verification results consisting of $\mathrm{X}, \mathrm{Y}$, and $\mathrm{Z}$ coordinate values. Data on radiation area shift data were calculated to know the average and were analyzed graphically and statistically using one sample T-test. A shift at the $\mathrm{X}$ coordinate was $0.32 \mathrm{~cm}, \mathrm{Y}$ coordinate was $0.20 \mathrm{~cm}$, and $\mathrm{Z}$ coordinates was $0.34 \mathrm{~cm}$. The application of Loxon Body Mask caused shifts in the radiation field; the causes could be imperfect mask application, the radiotherapy staff or the patients themselves. The average value of the shift in the radiation area in patients using Loxon Body Mask immobilization tool at $\mathrm{X}, \mathrm{Y}$, and $\mathrm{Z}$ coordinate was less than the tolerance value of $0.5 \mathrm{~cm}$.
\end{abstract}

Keywords: loxon body mask, immobilization, coordinates verification

\section{Introduction}

Liver cancer is the third most common malignant cancer in the world (Bosetti, Turati, \& La Vecchia, 2014; Feng \& Ben Josef, 2011). In 2008, there were 749,000 and 697,000 cases resulting in deaths from liver cancer, increasing in 2012 to 782,000 new cases (Lafaro, Demirjian, \& Pawlik, 2015). Most primary liver cancers 75\% to $90 \%$ are Hepatocellular Carsinoma which is a malignant tumor of parenchyma cells of the liver (Center \& Jemal, 2011).

Many types of treatments are available for healing liver cancer such as surgery and liver transplantation, but these treatments are only for small cancer sizes. The supporting measures are Chemo Embolization and radiotherapy(Ardiansyah, 2013). The role of radiation therapy in HCC cases is to reduce tumor size and avoid excessive liver toxicity (Klein \& Dawson, 2013).

Patient movement during radiation will increase the side effects received by the patient (Beyzdegoglu, 2010). According to the research conducted by Eccles et.al, radiation in the abdominal area especially the liver has a shift range of 5-50 mm when breathing freely without using an immobilized device (Eccles, Brock, Bissonnette, Hawkins, \& Dawson, 2006). In the research conducted by Lee et.al, shifts in the abdomen and pelvis in patients without using immbolization are quite large with an average of $7.5 \mathrm{~mm}$ (Lee et al., 2014)

At the MRCCC Siloam Hospital Semanggi, efforts were made to increase the accuracy of radiation therapy in the abdominal and pelvic area using an immobilization device in the form of a Body Loxon Mask. In addition to minimizing the patient's body movements, Loxon Body Masks can also make radiotherapists easier to set-up patients because this mask also has a reference point(Berta, n.d.). However, after verification, there was still a shift in the radiation field in the form of the identified $\mathrm{X}, \mathrm{Y}$, and $\mathrm{Z}$ coordinates. 


\section{Method}

This research was descriptive quantitative aiming to describe and analyze the effectiveness of Body Loxon Mask against the shifting of X, Y, and Z coordinates field in Hepatocellular Carsinoma patients using On Board Imager (OBI). The research population were all patients with clinical Hepatocellular Carsinoma in 2013-2017 in Radiotherapy Installation of MRCCC Siloam Hospital Semanggi amounted to 10 patients. Research samples were taken from subjects who met the inclusion criteria: Radiated at MRCCC Siloam Semanggi Hospital, using a Body Loxon Mask immobilization tool and verification was performed in every radiation or 20 times using Varian LINAC machine equipped with On Board Imager.

The data of patients who had radiation in the case of Hepatocellular Carsinoma with RapidArc technique and verified in every radiation (20 times) with ARIA Software. The data analysis began after obtaining the results from ARIA Software in the form of radiating field shift numbers at coordinates X, Y, and Z. The collected data were processed statistically to find the average value of the shift in each radiation fraction that had irradiation field verification. The results of data processing were calculated using the $t$ One Sample hypothesis testing to find out the average value obtained was within the tolerance limit of shifting tolerance or not.

\section{Results and Discussion}

Based on observations made, that was, taking daily patient shift data in the case of Hepatocellular Carsinoma obtained from ARIA Software at the MRCCC Siloam Semanggi Hospital, it was obtained 10 patients who did daily verification using OBI for 20 days in the form of shifting the radiation area on the axis of $\mathrm{X}$, $\mathrm{Y}$, in each faction as shown in Table 1.

Table 1 . Average daily verification of the $\mathrm{X}, \mathrm{Y}$, and $\mathrm{Z}$ coordinates in fractions 1 to 20

\begin{tabular}{cccccccc}
\hline Fraction & \multicolumn{3}{c}{ Shift Coordinate Point } & \multirow{2}{*}{ Fraction } & \multicolumn{3}{c}{ Shift Coordinate Point } \\
\cline { 7 - 8 } 1 to 10 & $X$ & $Y$ & $Z$ & 11 to 20 & $X$ & $Y$ & $Z$ \\
\hline 1 & 0.28 & 0.18 & 0.24 & 11 & 0.36 & 0.25 & 0.44 \\
2 & 0.21 & 0.24 & 0.29 & 12 & 0.28 & 0.19 & 0.29 \\
3 & 0.23 & 0.18 & 0.37 & 13 & 0.41 & 0.16 & 0.46 \\
4 & 0.27 & 0.31 & 0.26 & 14 & 0.31 & 0.23 & 0.31 \\
5 & 0.43 & 0.27 & 0.26 & 15 & 0.38 & 0.23 & 0.31 \\
6 & 0.23 & 0.14 & 0.51 & 16 & 0.36 & 0.11 & 0.27 \\
7 & 0.51 & 0.28 & 0.48 & 17 & 0.28 & 0.15 & 0.36 \\
8 & 0.30 & 0.18 & 0.46 & 18 & 0.17 & 0.20 & 0.34 \\
9 & 0.38 & 0.15 & 0.30 & 19 & 0.29 & 0.22 & 0.32 \\
10 & 0.48 & 0.31 & 0.50 & 20 & 0.31 & 0.19 & 0.22 \\
\hline
\end{tabular}

Table 1 show the average daily verification value exceeding $0.5 \mathrm{~cm}$ tolerance occurs on the Z-axis of the 6th and 10th fractions; In the results of the average daily shift of the radiation field, there are a number of fractions exceeding tolerance values, namely at the 6th fraction, 7th fraction, and 10th fraction at the $\mathrm{X}$ coordinate point and at the $\mathrm{Z}$ coordinate point. Based on the results of interviews with radiotherapists, shifts that occur in the irradiation field include poor patient positioning, errors among the lasers so as to make Set-up not optimal, patients are less cooperative, and the lack of reference marks on patient's body.

Especially in the X coordinates or laterally, it can be caused by the non-optimal set-up of the patient, or the patient condition who feels pain in certain parts and patient movements. Masking is not optimum because the size of the patient's body changes, while not attaching the entire mask connection on the Base Plate Body to avoid pain in the patient which can result in a lateral shift.

Meanwhile, the shift that occurs at $\mathrm{Z}$ coordinate point or in the longitudinal direction can be caused because the patients usually still wear pants or clothes when entering the radiation room, patients who only lower their pants during set-up can affect the center sign location. The loss or shift of the centration sign (midpoint) on the patient's body can also cause a shift in the longitudinal direction because the radiotherapist only performs the Set-up using the markings on the right and left sides of the patient's body.

Figure 1 is showed the average shift of the radiation area at the coordinates $\mathrm{X}, \mathrm{Y}$, and $\mathrm{Z}$ for 20 days or 20 times from the radiation fraction. Judging from the average value above, the $\mathrm{X}$ coordinate point in the 7 th fraction 
exceeding the tolerance limit value of $0.5 \mathrm{~cm}$ and on the 10th day, the value is high enough to almost reach the tolerance value. At the $\mathrm{Y}$ coordinate point, there is no value of a large radiation field shift or exceed the predetermined tolerance value. At the $\mathrm{Z}$ coordinate point, there are two values exceeding the tolerance, namely at fractions 6 and 13, also obtained quite high value of radiation area shift almost reaching tolerance value.

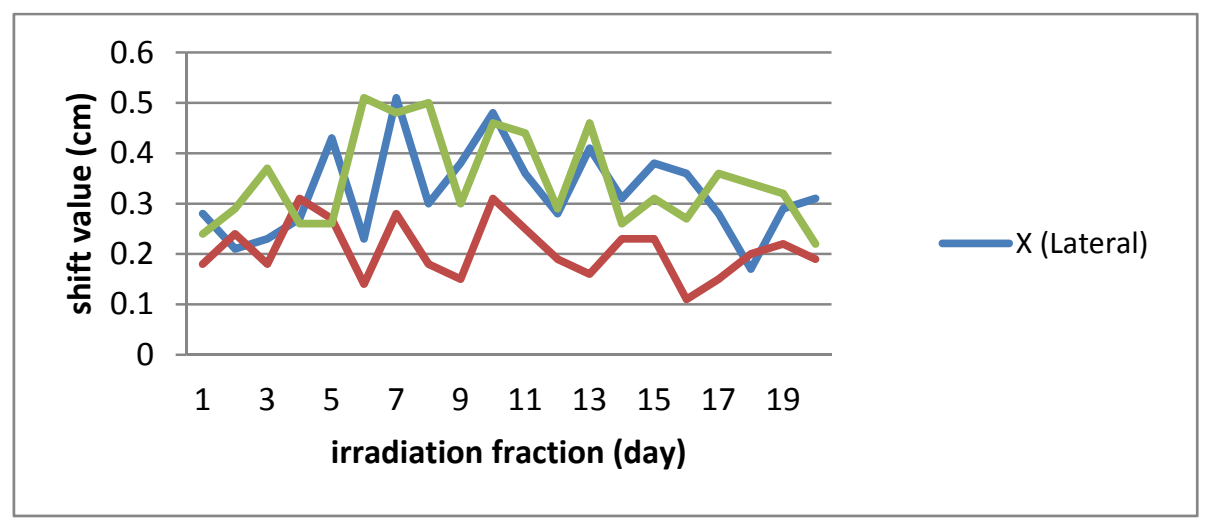

Figure 1. Average shift of the radiation area at coordinates $\mathrm{X}, \mathrm{Y}$, and $\mathrm{Z}$ for 20 times radiation fraction For the statistical calculation, decision making results of the calculation of $\mathrm{T}$ test one sample can be obtained from a comparison of the Sig. with a confidence level of $95 \%$, so the $\mathrm{p}$ value is 0.05 . If the Sig value $<0.05$ then $\mathrm{H} 0$ is rejected, and if the Sig value $>0.05$ then $\mathrm{H} 0$ is accepted. Calculation of one sample $t$ test using software statistical application. The results of the calculation of one sample $t$ test is as shown in Table 2

Table 2. The overall mean and standard deviation of $\mathrm{X}, \mathrm{Y}$, and $\mathrm{Z}$

\begin{tabular}{ccccccc}
\hline $\begin{array}{c}\text { Coordinate } \\
\text { point }\end{array}$ & $N$ & Mean & $\begin{array}{c}\text { Standard } \\
\text { Deviation }\end{array}$ & $P$ & $\begin{array}{c}\text { Hypotesis } \\
\text { Nol }\end{array}$ & Results \\
\hline $\mathrm{X}$ & 200 & 0,32 & 0,89 & 0.00 & Rejected & Fit \\
$\mathrm{Y}$ & 200 & 0,20 & 0,56 & 0.00 & Rejected & Fit \\
$\mathrm{Z}$ & 200 & 0,34 & 0,94 & 0.00 & Rejected & Fit
\end{tabular}

In the overall average results of the radiation field shift (Table 2), it is found at the $X$ coordinate point by 0.32 $\mathrm{cm}$, at the $\mathrm{Y}$ coordinate point by $0.20 \mathrm{~cm}$, and at the $\mathrm{Z}$ coordinate point by $0.34 \mathrm{~cm}$. From the results, it shows that the shift in the radiation field in Hepatocellular Carsinoma patients using the Body Loxon Mask immobilization device does not exceed the tolerance limit; according the results of the statistical test of one sample $\mathrm{T}$ test, it is obtained a significance value of 0.00 with a $95 \%$ confidence level. So that the $\mathrm{p}$ value is 0.05 . Therefore, the significance value is $<0.05$, so that $\mathrm{H} 0$ is rejected which means that the alternative hypothesis is applicable, namely shift in the $\mathrm{X}, \mathrm{Y}$, and $\mathrm{Z}$ coordinates point from the first fraction to the 20th fraction has no significant radiation field shift exceeding the tolerance value of $0.5 \mathrm{~cm}$. This shows that the use of Loxon Body Masks at MRCCC Siloam Hospital Semanggi is good enough to minimize the movement of patients. Therefore, the accuracy is very important in carrying out radiation according to the principle of radiotherapy to provide the optimal dose to the target and to provide the minimum dose to the surrounding organs.

\section{Conclusions}

The preparation and set-up of patients in the Loxon Body Mask immobilization device at the MRCCC Siloam Hospital Semanggi is quite good in minimizing patient movements. The average value of the radiation area at the $\mathrm{X}$ coordinate point is $0.32 \mathrm{~cm}$, the $\mathrm{Y}$ coordinate point is $0.2 \mathrm{~cm}$, and at the $\mathrm{Z}$ coordinate point is $0.34 \mathrm{~cm}$ which remains below the tolerance value of $0.5 \mathrm{~cm}$.

\section{Acknowledgements}

We would like to thank the Director of Radiodiagnostic and Radiotherapy Department of Politeknik Kesehatan Kementerian Kesehatan Jakarta II, Ministry of Health for his contributions during the study. We are sincerely grateful to the Directors, Radiographers, Medical Physicist and staffs of MRCCC Siloam Semanggi Hospital Jakarta for their valuable contributions, facilities, assistance and constructive suggestions during our study. 


\section{References}

Ardiansyah, A. A. I. (2013). Tinjauan Oncology terhadap Terapi Radiasi (Radiation Therapy) untuk Kanker Hati. Artikel Ilmiah Jurnal Kesehatan. Available from https://www.researchgate.net/publication/269347321_Tinjauan_Oncology_terhadap_Terapi_Radiasi_Radiat ion_Therapy_untuk_Kanker_Hati

Beyzdegoglu, M. (2010). Basic Radiation Oncology. Berlin: Springer.

Bosetti, C., Turati, F. \& La Vecchia, C. (2014). Hepatocellular carcinoma epidemiology. Best Practice and Research: Clinical Gastroenterology, 28(5), 753-770. https://doi.org/10.1016/j.bpg.2014.08.007

Center, M. M. \& Jemal, A. (2011). International Trends in Liver Cancer Incidence Rates. Cancer Epidemiology Biomarkers \& Prevention, 20(11), 2362-2368. https://doi.org/10.1158/1055-9965.EPI-11-0643

Eccles, C., Brock, K. K., Bissonnette, J. P., Hawkins, M. \& Dawson, L. A. (2006). Reproducibility of liver position using active breathing coordinator for liver cancer radiotherapy. International Journal of Radiation Oncology Biology Physics, 64(3), 751-759. https://doi.org/10.1016/j.jjrobp.2005.05.066

Feng, M. \& Ben Josef, E. (2011). Radiation Therapy for Hepatocellular Carcinoma. Seminars in Radiation Oncology, 21(4), 271-277. https://doi.org/10.1016/j.semradonc.2011.05.002

Klein, J. \& Dawson, L. A. (2013). Hepatocellular carcinoma radiation therapy: Review of evidence and future opportunities. International Journal of Radiation Oncology Biology Physics, 87(1), 22-32. https://doi.org/10.1016/j.ijrobp.2012.08.043

Lafaro, K. J., Demirjian, A. N. \& Pawlik, T. M. (2015). Epidemiology of Hepatocellular Carcinoma. Surgical Oncology Clinics of North America, 24(1), 1-17. https://doi.org/10.1016/j.soc.2014.09.001

Lee, J. ., Kim, C., Park, Y., Yoon, W., Lee, N. \& Yang, D. (2014). Interfractional variability in intensity-modulated radiotherapy of prostate cancer with or without thermoplastic pelvic immobilization, (May 2013), 94-99. https://doi.org/10.1007/s00066-013-0452-9

\section{Copyrights}

Copyright for this article is retained by the author(s), with first publication rights granted to the journal.

This is an open-access article distributed under the terms and conditions of the Creative Commons Attribution license (http://creativecommons.org/licenses/by/4.0/). 